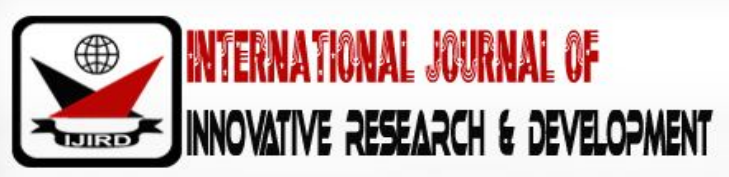

ISSN 2278 - 0211 (Online)

\section{Correlation between Body Mass Index (BMI) and Hypertensive Tendency among Nigerians Resident in Makurdi, Benue State-North Central, Nigeria}

Dr. Eru Emmanuel
Lecturer, Department of Physiology, College of Health Sciences, Benue State University, Nigeria
Christian Onahinon
Co-Researcher, Department of Physiology, College of Health Sciences, Benue State University, Nigeria
Dr. Julie Ibu
Chief Inspector, National Youth Service Corps. Benue State NYSC secretariat Head Quarter Nigeria
Dr. Nndunno Akwaras
Senior Registrar, Department of Family Medicine, Federal Medical Center, Nigeria
Dr. Adugba Augustine
Lecturer, Department of Physiology, College of Health Sciences, Benue State University Nigeria
Saalu Linus
Lecturer, Department of Anatomy, College of Health Sciences, Benue State University, Nigeria
John Ibu
Lecturer, Department of Physiology, College of Health Sciences, Benue State University Nigeria

\section{Abstract:}

Hypertension is on the rise worldwide, most especially among the developing nations like Nigeria (WHO, 2012). This present study was designed to find out the correlation between body mass index and hypertensive tendency among Nigerians resident in Makurdi Benue State, North Central Nigeria. In order to get empirical data, anthropometric measurements were done. This includes, weight, height, body mass index, waist circumference, hip circumference waist - hip ratio and, mid arm circumference, Blood pressure measurements were done using digital BP apparatus. Results: Overall prevalence of overweight and obesity were (19.7\%) and (7.9\%) respectively. Males accounted for $6.7 \%, 3.4 \%$ and females $13.0 \%$ and $4.0 \%$ respectively. The BMI, WC, HC WHR, and MAC). Were 27.95 $\pm 5.0,78.49 \pm 13.43,93.49 \pm 13.16$, and WHR 0.86 $\pm 0.06, \mathrm{MAC}$ $27.64 \pm 6.19$ formaleand $26.62 \pm 5.2,80.81 \pm 13.13,-95.99 \pm 10.6$, and $0.87 \pm 0.05,28.26 \pm$

6.62 forFemalerespestivelyThere are significant difference( $\mathrm{P} \leq 0.01$ ) The systolic blood pressure (SBP), $123.74 \pm 9.30$ for male and 123.31 \pm 9.43 for female and diastolic blood pressure of $84.74 \pm 8.59$ (male) and $84.20 \pm 8.42$ female respectively. There were not statistically significant different $(\mathrm{P} \geq 0.05)$.

Keywords: Body mass index, anthropometric measurements, obesity, hypertension

\section{Introduction}

Hypertension is the leading preventable cause of premature death worldwide (Ania,2004).It is a well-recognized silent killer non-communicable disease and is the most common cause of morbidity and mortality in human race worldwide (WHO, 2012, Rajakumar et al., 2012.).Raised blood pressure is also a major risk factor for cardiovascular disease, coronary heart disease, ischemic as well as hemorrhagic stroke(Adediran et al.,2013,Okpara et al.,2013,Abiodun et al.,2011). Complications of hypertension include heart failure, peripheral vascular disease, renal impairment, retinal hemorrhage and visual impairment. (Kearney et al., 2013).

The global prevalence of hypertension has been on the rise both in the developed nations as well as in the developing Sub-Saharan Africa (Persion,1991). World health Organization estimates about 972 million people to be living with hypertension currently with a prevalence rate of $36.4 \%$ in 2000 alone and around $40 \%$ in 2008. (WHO, 2012). This figure was 
projected to increase to 1.54 billion in the year 2030.Worldwide raised blood pressure is estimated to cause 7.5 million deaths, about $12.8 \%$ of the total of all deaths. This accounts for 58 million disability adjusted life per year. (WHO, 2013).

However, because of population growth, rapid urbanization and ageing the number of people with uncontrolled hypertension rose from 600 million in 1980 to nearly one billion in 2008. Across the World Health Organization regions, the prevalence of raised blood pressure was highest in Africa, where it was $46 \%$ for both sexes combined. In all WHO regions, men have slightly higher prevalence of hypertension than women and are consistently high, among the low, and middle-income countries, all having rates of around 40\% (Gupta et al., 2013).

In Nigeria, the prevalence of hypertension has reached an epidemic proportion and has become a major public health concern. It was estimated that one out of five male Nigerians is suffering from high blood pressure (Adewole 2017.).The condition has also been reported to be compounded by increase in excessive salt intake in the diet and lack of physical activity, excessive cigarette smoking and alcohol consumption (Elias et al., 2011, Meueton et al.,2005).

Obesity isan acknowledged risk factor for the development of hypertension and other cardiovascular diseases (Rotimi et al., 1999). The body mass index (BMI) is commonly used to measure the degree of obesity. Body mass index (BMI),weight in kilograms divided by square of the height in meter $\left(\mathrm{Kg} / \mathrm{m}^{2}\right)(\mathrm{CDC}, 2009)$.It is estimated from a person weight and height and is a simple,inexpensive measure of weight - for -height that is clinically used to classified individual as underweight, normal weight or obese (WHO,2006). However, the usefulness of BMI is limited as it does not take account of body fat distribution in different human population (WHO,2002).This limitation of BMI, therefore necessitated the need for other anthropometric profiles that take account of regional abdominal fat distribution (Wellborn et al.,2003).Previous studies have demonstrated that regional abdominal fat distribution is related closely to raise in blood pressure (Kartman et al., 1996).For example,waist circumference (WC), hip circumference (HC), skin fold thickness(SFT), mid arm circumference (MAC), and waist -hip ratio (WHR) are anthropometric measures that indicate obesity (Yusuf et al.,2004).

Overweight and obesity have been associated with two-to six folds increase in the risk of developing hypertension (Deshmvkh et al,2006). There is paucity of information of predicting hypertension using anthropometric indices in Northcentral Nigeria. Therefore, this study was designed to correlate the BMI and high blood pressure tendency among Nigerians in Makurdi, -North - central Nigeria.

\section{Materials and Methods}

\subsection{Study Design}

This investigation is a cross-sectional study, conducted between February 2016 and March 2017 among Nigerians resident in Makurdi Benue State North Central Nigeria. It is a non-experimental design in which questionnaires were administered for collection of empirical data. The questionnaires intended to obtain socio-demographic information of the participants. It was divided into three sections- a demographic section, concerned with age, sex, ethnic group and region of resident, while the second section deals with history of lifestyle and the final section involves the laboratory investigations. The age range was between 18 and 65 years. A total of 1851 subjects were recruited for the study.

\subsection{Area of Research and Population Sampled}

The area of study is in Makurdi, Benue State among Nigerian population. The study cut across all professions. The age range was between 18 and 65 years. The total population of participants recruited for this study was (n-1189(64.2\%) males and $(\mathrm{n}=662(35.8 \%)$ females.

\subsection{Sampling Technique}

Sampling technique was done by sequential randomization according to the modified method of Denga and Ali (1998). From a target population of 3500 Nigerians population. During this period of study, a total number of 1851. Subjects were selected.

\subsection{Consent/ Ethical Approval}

Informed written consent was obtained from all the participants for the study. Ethical approval was obtained from ethical Research Committee of the Benue State University Teaching Hospital Makurdi. (BSUTH/ MKD/ HREC/ 2013B/ 2017/ 0038)

\subsection{Exclusion/ Inclusion Criteria}

Exclusion criteria includes: known hypertension, diabetes mellitus, smokers, alcoholism, drugs medication, pregnant, lactating women and age below 18 and above 65 years. Inclusion criteria are age between 18 -65 years old and apparently healthy adult Nigerians, with no family history of hypertension and diabetes mellitus. 


\subsection{Anthropometric Measurements}

In order to get empirical data, six anthropometric variables were taken: weight, height, waist circumference, hip circumference, skin fold and mid arm circumference. All measurements were performed according to WHO recommendation (WHO expect Committee, 1995).

Weight was measured to the nearest $0.1 \mathrm{~kg}$ with shoes off, and light clothes on using portable bath room scale (Harson Emperors, model; H89 DK Blue, China), placed on a smooth hard surface.

Height was also measured to the nearest 0.1 meter using a portable stadiometer with the subject standing on a flat ground without shoes and face gear. BMI was computed from weight divided by the square of height $\left(\mathrm{kg} / \mathrm{m}^{2}\right)$.

Waist circumference, mid arm circumference and hip circumference were measured using an elastic measuring tape. WC was measured in a standing position by passing inelastic tape around the waist at the level of iliac crest and midway between the umbilical and pubic symphysis to the nearest $0.1 \mathrm{~cm}$.Hip circumference $(\mathrm{HC})$ was also measured to the nearest $0.1 \mathrm{~cm}$ around the largest protrusion of the buttock (Nwankwo et al.,2013)

\subsection{Blood Pressure Measurements}

Blood pressure were measured according to the standard condition by auscultatory and palpation method using mercury sphygmomanometer and digital blood pressure machine. The subjects were first seated in a chair and made to relax and comfortable for at least five minutes. The first reading was discarded because it might be influenced by anxiety. Three readings were taken 15 minutes intervals and average reading taken. Hypertension was defined as SBP $\geq 140 \mathrm{mmHg}$ and $\mathrm{DBP} \geq 90 \mathrm{mmHg}$ according to World Health organization (2003) recommendation. All measurements were carried out under standard condition by trained research staff.

\subsection{Statistical Analysis}

Data were expressed as mean \pm SEM using statistical package for Social Sciences (SPSS version 20). Data were also subjected to one-way analysis of variance. (ANOVA). Descriptive statistics were deployed to test the comparative significant of the relationship between anthropometric independent variables and hypertension $\quad \mathrm{P} \leq 0.05$ was considered statistically significant.

\section{Results}

Results of data sampled using one thousand eight hundred and fifty-one (1851) randomly selected among Nigerians resident in Makurdi. This made up 1189 (64.2\%)-males with a mean age 32.67士8.87 years and 662 (35.8 \%) females with mean age $32.30 \pm 8.91$ years given a ratio of male to female as $2: 1$ took part in the study.

\begin{tabular}{|c|c|c|c|c|c|c|c|c|}
\hline \multicolumn{9}{|c|}{ Male } \\
\hline Age & $\begin{array}{c}\text { Number } \\
\text { Of } \\
\text { Subjects }\end{array}$ & $\begin{array}{c}\text { Systolic } \\
\text { Blood } \\
\text { Pressure } \\
(\text { Mmhg) }\end{array}$ & $\begin{array}{c}\text { Diastolic } \\
\text { Blood } \\
\text { Pressure } \\
(\text { Mmhg) }\end{array}$ & $\begin{array}{c}\text { Body Mass } \\
\text { Index } \\
\left(\mathrm{Kg} / \mathrm{M}^{2}\right)\end{array}$ & $\begin{array}{c}\text { Number } \\
\text { Of } \\
\text { Subjects }\end{array}$ & $\begin{array}{c}\text { Systolic Blood } \\
\text { Pressure } \\
(\text { Mmhg) }\end{array}$ & $\begin{array}{c}\text { Diastolic Blood } \\
\text { Pressure } \\
(\mathrm{Mmhg})\end{array}$ & $\begin{array}{c}\text { Body Mass } \\
\text { Index (Kg/ M } 2)\end{array}$ \\
\hline $20-29$ & 433 & $123.9 \pm 0.5$ & $83.6 \pm 0.3$ & $26.5 \pm 0.3$ & 155 & $124.2 \pm 0.7$ & $83.4 \pm 0.6$ & $26.8 \pm 0.4$ \\
\hline $30-39$ & 369 & $123.7 \pm 0.5$ & $83.7 \pm 0.3$ & $26.7 \pm 0.3$ & 248 & $124 \pm 0.6$ & $85.3 \pm 0.6$ & $27.4 \pm 0.3$ \\
\hline $40-49$ & 197 & $124.7 \pm 0.6$ & $84.2 \pm 0.6$ & $26.8 \pm 0.3$ & 169 & $124.6 \pm 0.8$ & $84.9 \pm 0.5$ & $26.7 \pm 0.5$ \\
\hline $50-59$ & 124 & $124.6 \pm 0.8$ & $85.8 \pm 0.7$ & $26.3 \pm 0.5$ & 83 & $131.6 \pm 1.2$ & $85.1 \pm 0.9$ & $27.4 \pm 0.5$ \\
\hline$\geq 60$ & 66 & $132.3 \pm 1.5$ & $85.7 \pm 1.0$ & $26.8 \pm 0.6$ & 7 & $141.4 \pm 4.9$ & $83.7 \pm 2.9$ & $28.2 \pm 1.7$ \\
\hline Mean & 1189 & $124.5 \pm 0.3$ & $85.8 \pm 1.0$ & $26.6 \pm 0.2$ & 662 & $125.4 \pm 0.3$ & $84.7 \pm 0.3$ & $27.1 \pm 0.2$ \\
\hline
\end{tabular}

Table1

Table1 Shows mean value ( \pm SEM) of systolic blood pressure (SBP), diastolic blood pressure (DBP) and BMI with age distribution for both sexes. The table depicted the mean value

of systolic blood pressure (SBP) of $123.9 \pm 0.5 \mathrm{mmHg}$ and, diastolic blood pressure of $83.6 \pm$

$0.5 \mathrm{mmHg}$ for male and SBP of $124 \pm 0.7 \mathrm{mmHg}$ and DBP of $83.4 \pm$

$0.6 \mathrm{mmHg}$ for female respectively. The mean body mass index of $26.7 \pm 0.3 \frac{\mathrm{kg}}{\mathrm{m} 2}$ for male and $28.2 \pm 1.7 \mathrm{~kg} /$ $\mathrm{m} 2$.for female.there were not statistically significant different $(\mathrm{P} \geq 0.05)$. 


\begin{tabular}{|c|c|c|c|}
\hline Variable & Male & Female & Combined \\
\hline $\mathrm{N}$ & 1189 & 662 & 1851 \\
\hline BMI $\left(\mathrm{kg} / \mathrm{m}^{2}\right)$ & $27.95 \pm 5.0$ & $26.62 \pm 52$ & $27.82 \pm 4.83$ \\
\hline Waist Circumference $(\mathrm{cm})$ & $78.49 \pm 13.2$ & $80.81 \pm 13.13$ & $80.08 \pm 10.43$ \\
\hline Hip Circumference $(\mathrm{cm})$ & $93.83 \pm 13.16$ & $95.99 \pm 10.6$ & $92.44 \pm 12.2$ \\
\hline WHR & $0.86 \pm 0.06$ & $0.87 \pm 0.05$ & $0.87 \pm 0.06$ \\
\hline MAC $(\mathrm{cm})$ & $27.64 \pm 6.1$ & $28.26 \pm 6.62$ & $27.47 \pm 6.1$ \\
\hline
\end{tabular}

Table 2: Presents the Comparison of Anthropometric Variables Based on Genders

Table 2: Presents the comparison of anthropometric variables based on genders (BMI, WC, HC/ WHR, MAC). Of $27.95 \pm 5.078 .49 \pm 13.43,93.49 \pm 13.16$ and $W H R-0.86 \pm 0.06,27.64 \pm 6.19$, for male and $26.62 \pm 52,80.81 \pm$ $13.13,-95.99 \pm 10.6$, and $0.87 \pm 0.05,28.26 \pm 6.62$ for Female respestively. The (WC, HC, WHR) are significant $(\mathrm{P} \leq 0.01)$ The male are more overweight than females subjects. There are however remarkably lower hip circumference and WHR in male when compared to that of female subjects. This accounts for higher obesity in female than male. $(\mathrm{P} \leq 0.05)$

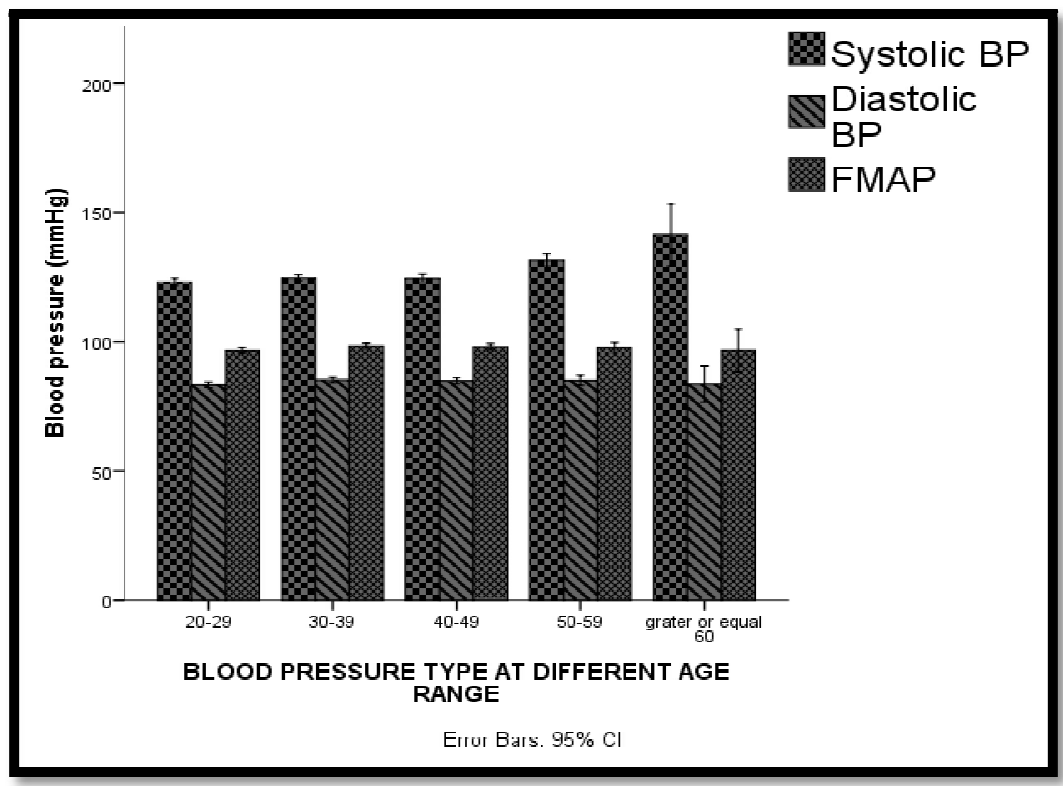

Figure 1: Shows SBP, DBP and MAP for Different Age Range

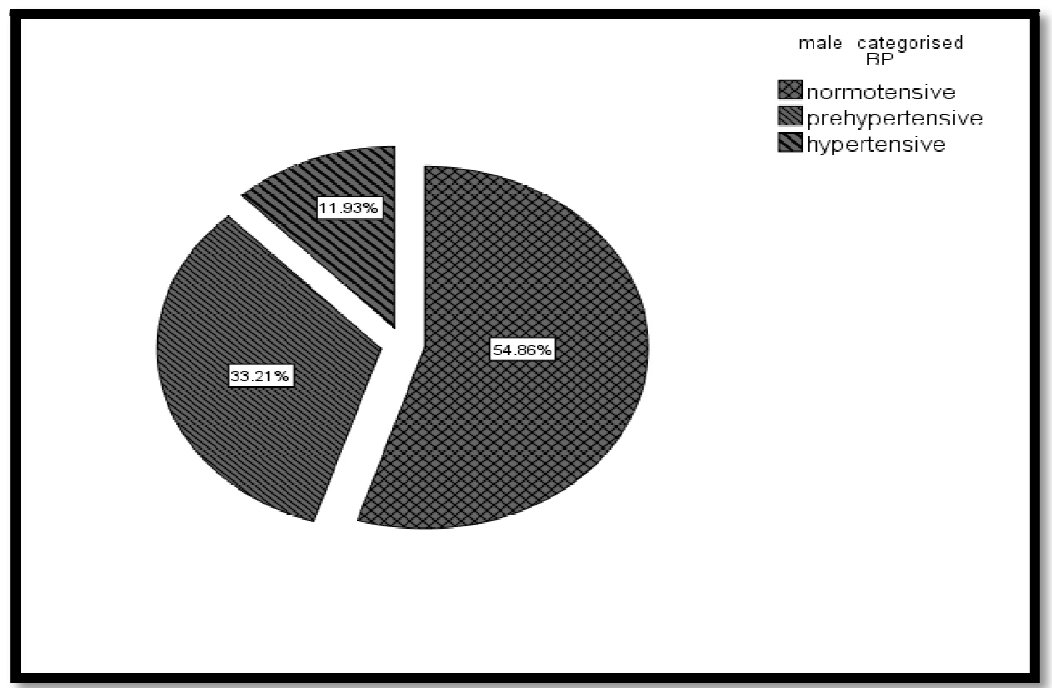

Figure 2: Shows the Percentage of Hypertension for Male Subjects

The pie chart also shows that percentage of pre hypertensive subjects. The higher prevalence of pre hypertension suggests possible higher prevalence of hypertension in future if not controlled. 


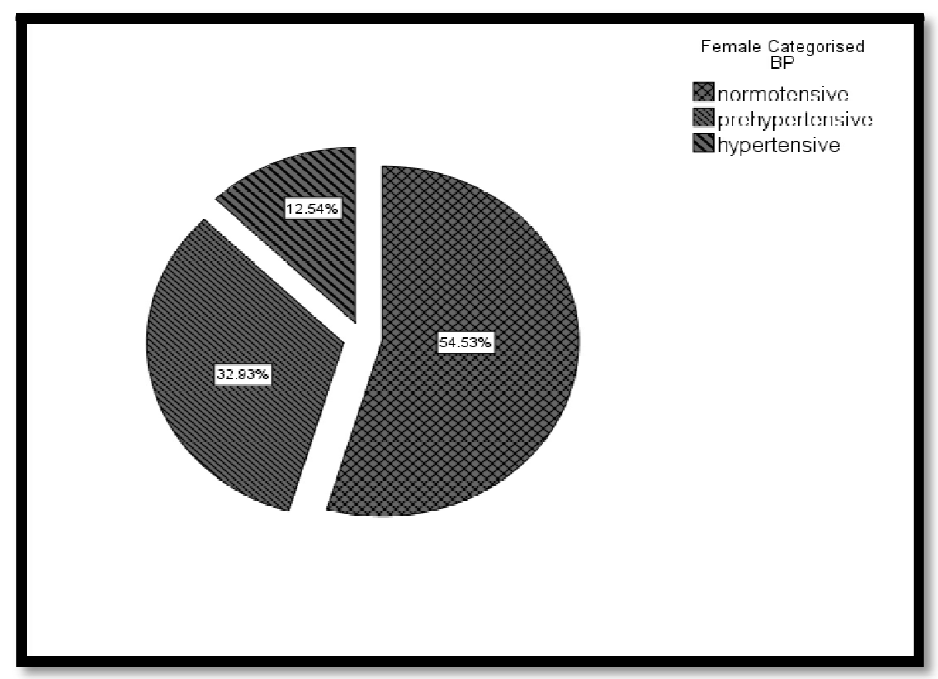

Figure 3: Shows Prevalence of Hypertension in Female Subjects

From the figure above, just as in the male subjects, there was a higher prevalence of pre hypertension, which suggest a possible rise in hypertension prevalence in both male and female residence if not controlled.

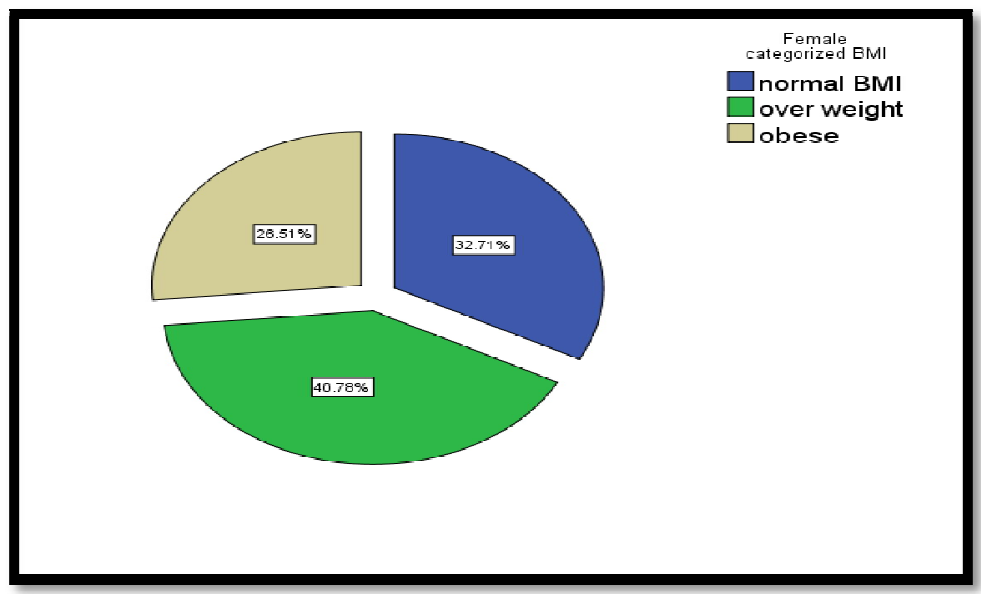

Figure 4: Shows Prevalence of Obesity in Female Subjects

From the figure above $32.71 \%$ of the female subject had normal BMI within physiological range. $40.78 \%$ of the female subject had BMI above the normal physiologic range but less than $30 \mathrm{~kg} / \mathrm{m}^{2}$, this represent the over weight class. The figure suggests a possible rise in the prevalence of obesity in future.

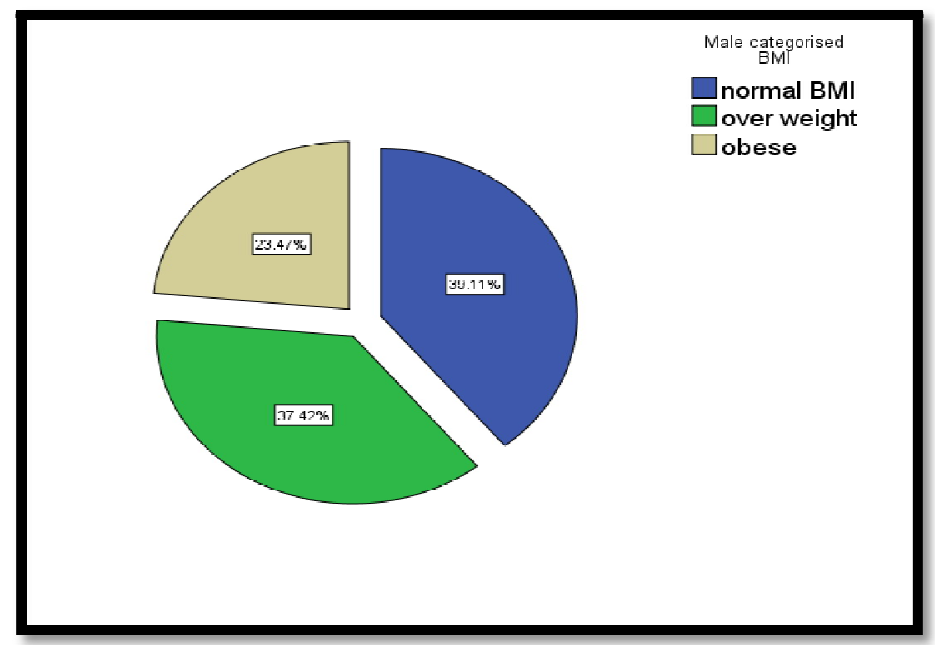

Figure 5: Shows the Prevalence of Obesity in Male Subjects 
From the figure above $39.11 \%$ of the male subject had normal BMI within physiological range. $37.42 \%$ of the male subject had BMI above the normal physiologic range but less than $30 \mathrm{~kg} / \mathrm{m}^{2}$, this represent the over weight class. This figure suggests a possible rise in the prevalence of obesity in future.

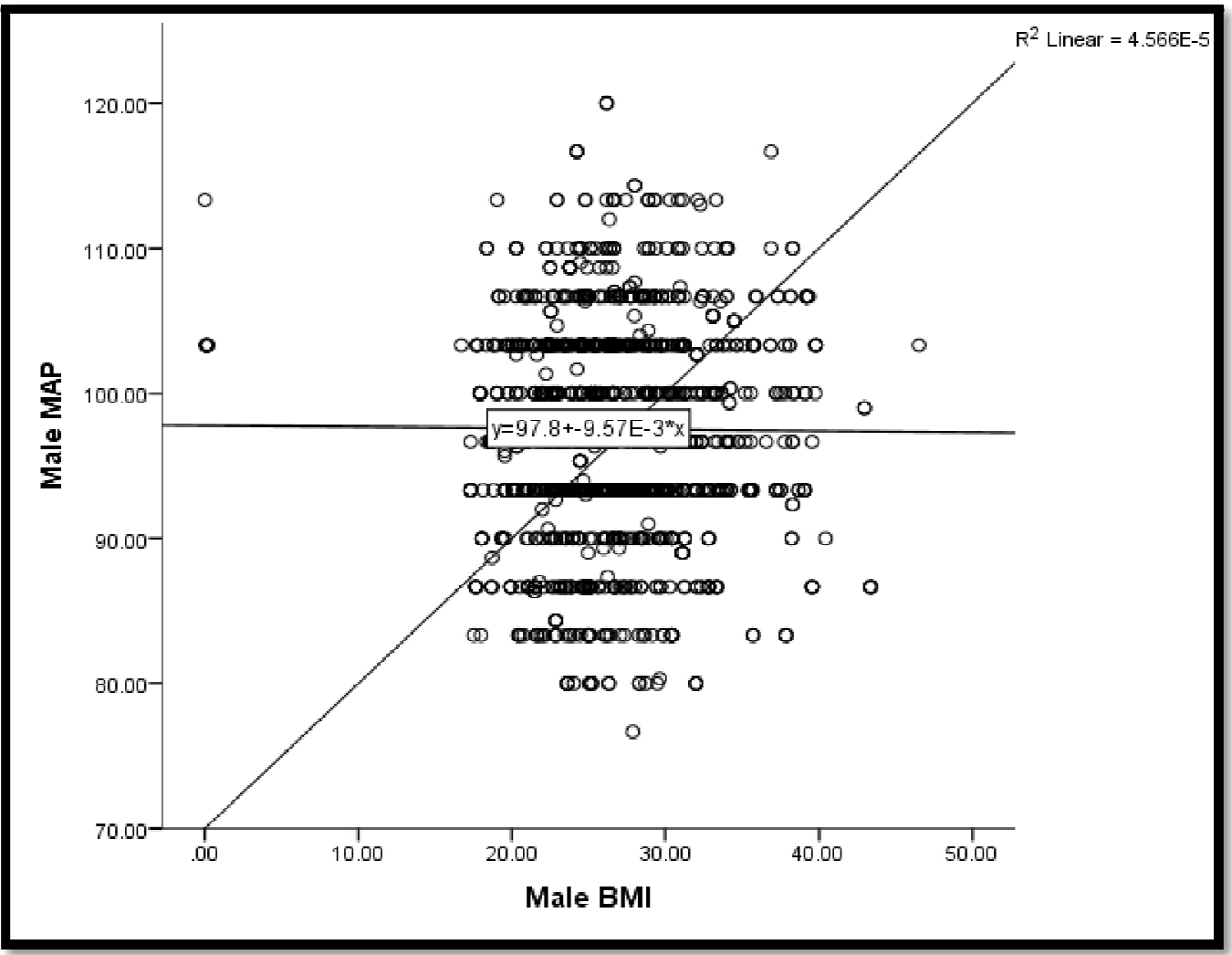

Figure 6: Shows the Scatter Plot between BMI and MAP for Male Subjects $(p<0.01)$

This shows that there is a statistical positive correlation between Mean arterial blood pressure and body mass index

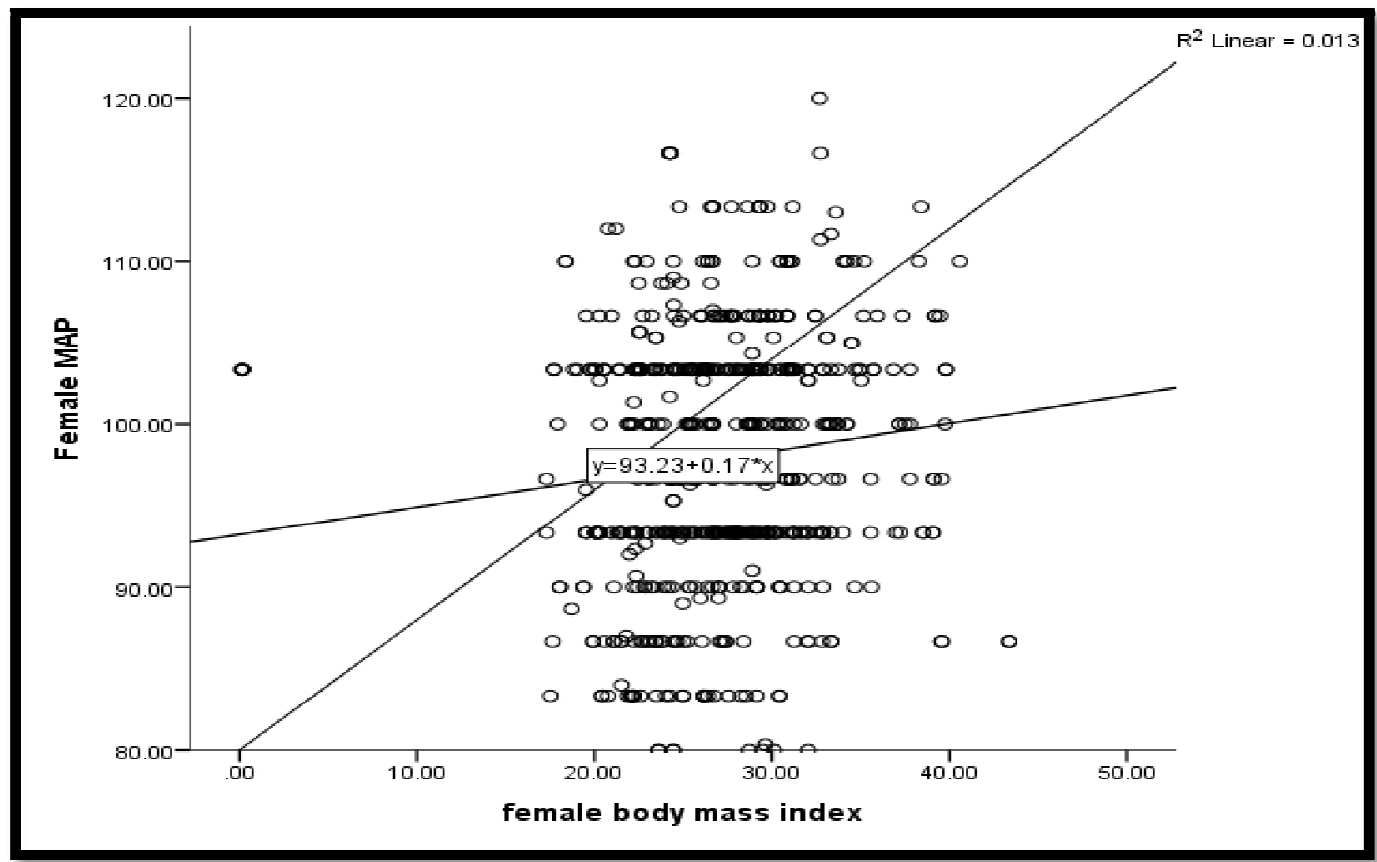

Figure7: Shows the Scatter Plot between BMI and MAP for Female Subjects 

$(\mathrm{p}<0.05)$.

This shows that there is a statistical positive correlation between Mean arterial blood pressure and body mass index

\section{Discussion}

The present study investigates the correlation between body mass Index and hypertensive tendency among Nigerians resident in Makurdi, North Central Nigeria.

The mean BMI was 27.95 \pm 5.0 male and $26.62 \pm 5.2$ female respectively. The mean SBP for the population was $123.74 \pm 9.60$, DBP $84.74 \pm 8.59$.The prevalence of hypertension in this study is slightly lower among males than females for all age categories (11.93\% and $12.54 \%)$ there was no significant different. $(\mathrm{p} \leq 0.05)$

This is in agreement with a similar study carried out by (Adedogin et al.,2008, Rotimi et al., 1999) in Southwest Nigeria. This results however, are in contrast to another more recent documentation which revealed higher prevalence of hypertension in Western Nigeria 46\%(Adediran et al., 2013, Adeoye et al., 2006).

Relationship between hypertension and body mass index and other anthropometric indices are quite evident in several studies (Mutuwa et al.,2006, Cappucio.,2004).

Fig 4. and fig 5. showed the prevalent of obesity and overweight in female subjects to be $26.51 \%$ and $40.78 \%$ whereas in male subjects the prevalence of obesity and overweight was $23.47 \%$ and $37.42 \%$. This study revealed that females are more overweight and obese than male. This is in lined with obesity rate which has been reported from $24 \%$ to $36 \%$ in developed nations and a global estimate of adult obesity. Current estimates from the Centre for Diseases Control indicate that approximately one-third of the population in the United States is obese and another third is overweight. In the present study the prevalent of overweight was $(40.78 \% \%)$ and obesity ( $26.51 \%$ in female and $37.42 \%$ and $23.47 \%)$ in male. This study however showed a low value in comparison to previous studies in Nigeria at Zaria (29\%) and Calabar (30\%).The general trend is on the rise.

It was also observed from this study that BMI and anthropometric variables such as WC, HC and WHR $78.49 .08 \pm 13.16,92.44 \pm 12.2,086 \pm 0.06$ for male and $80.81 \pm 13.0,94.99 \pm 10.6,0.87 \pm 0.05$ for female respectively. They are predictive indicators for hypertension. This finding is in agreement with previous studies (Li et al.; 2013, Czernic how etal.;2011, Park et al.;2009, Klein et al.;2007)

Fig 6 and Fig 7 (-Sctter plot) -Showed a strong positive correlation between BMI and MAP for both sexes. Relationship between body mass index, hypertension and MAP is quite evident in many studies (Ejike et al.; 2008). Most hypertensive subjects are overweight or obese and they generally lead a sedentary lifestyle, hardly engaged in physical activities, exhibit poor dietary habit such as consumption of high dese calories (junk foods) which are readily available at cheaper rate among Nigerians resident in Makurdi. Also, excessive cigarette smoking, and alcohol consumption which is a daily practice of people of Makurdi-. North Central Nigeria.

Overweight and obesity are major risk factors for the development of hypertension globally, particularly in the developing countries. High blood pressure is rapidly becoming a major cause of sudden death among Nigerians population. (Adienbo, 2012). Hypertension has been acknowledged to be the leading preventable cause of premature death worldwide. It is regarded as silent killer diseases.

Hypertension medically can be classified into two main categories. -primary (Essential hypertension) the cause is unknown (idiopathic) and secondary hypertension which causes can be related to renal, arterial stenos is or endocrine disorders. Persistent increased in arterial blood pressure can lead to heart failure due to excess workload as well as damage to the brain blood vessels (stroke) and instant death.

This investigation however, revealed that the body mass index and other anthropometric variables are indicators of body fat distribution and also risk factors for hypertension in Makurdi metropolis, North Central Nigeria.

\section{Conclusion and Recommendations}

We found that BMI is strongly associated with the development of hypertension. Hypertension has been a major cardiovascular risk factor and a leading cause of death among Nigerians as well as other developing Sub-Sahara Africa. Based on the findings of this study, the following recommendations are made.

- Nigerians resident in Makurdi should watch their diet by considering low calories and salt diet, stop smoking and excess consumption of alcohol.

- They should strongly commit to a change in lifestyle through the combination of a healthy diet and regular physical activity and exercise. Positive exercise has a positive effect on metabolism.

- Regular monitoring of blood pressure is recommended.

- Nutrition education programs should be introduced to enlighten the entire population in Nigeria about the danger of poor dietary habits.

\section{Acknowledgment}

The authors would like to express their gratitude to Prof John. O. Ibu for his mentorship, Mary Eduack,AdamuGabriel, and all that consented to participate in this study. 


\section{References}

i. Amira CO, Sokunbi DOB, Sokunbi A., The prevalence of obesity and its relationship with hypertension in an urban community. Data from world kidney day screening programmes. Inter J,Med Biomed, Ras 2012:16: 104610.

ii. America Diabetes Association, Standard of Medical in Diabetes 2010:2011(on line).Accessed 3rd Aug 2011.

iii. Adienbo OM, hart VO,Oyeyemi WA: High prevalence of obesity among indigenous residents of a Nigerians ethnic group. The kalabar is in the Niger Delta region of South -South Nigeria. GreenerJ: Med Sci 2012:2 (6) 152 -156.

iv. Ania Lichtarowke (2004); Obesity BBC world Service 2004 (15:22)

v. Centers for diseases control and prevention Diabetes Latest National Diabetes Statistics report 2014.

vi. Ekpenyong CE,Udokang NE, Akpan EE, Samson TC; Double burden -Non -communicable disease and risk factors evaluation in Sub -Saharan Africa. The Nigeria experience. European J.Sus Dev.2012:1 (2) 249-270.

vii. Egwurugwu JN, Nwa for A: Prolonged exposure to oil and gas flares ups, the risks for hypertension. American journal of Health Research 2013:1 (3) 65-72.

viii. Pickering GW: The natural history of hypertension. British Medical Bulletin1952, 8(4) 305 Pub Med.

ix. Persian TA. Cardiovascular disease in developing countries, myths relation and opportunities, cardiovascular, drugs and therapy sponsored by the International Society of cardiovascular Pharmacotherapy 1991 13(2) 95 -104 (Pub Med).

x. Gupta R. hypertension in India -definition, prevention and evaluation. Journal of the Indian Medical Association (1999-97(3): 74-80 (Pub Med)

xi. Flegal KM, CarrollMD, Cynthia L. Ogden and Curtin US, adults 1999-2008. JAMA :303(3),235-241.

xii. JaffaPKP, Nwa for A,Adienbo MO, correlation between body mass index and peak expiratory flow rates of an indigenous Nigeria population in the Niger Delta region, Ressa J. Recent Sci 2013;2 (2) 28-32.

xiii. Popkin B.M. (2002). The shift in stages of Nutrition Transition in the developing world, Differ from past experience. Pub Health - Nutri 5 -205-215.

xiv. Rajakumar S, Ann LL,Gill PK,Xim GW, Kalasalingam A. A. Comparative study of hypertension, diabetes mellitus and obesity among Malaysians in Urban region -A cross -sectional study. Int J.res Pharm. Sci 2012 :3 (1) 38-44.

xv. World Health Organization 2014, obesity and overweight fact sheet in 311:2014.

xvi. World Health Organization. Global status report on non-communicable disease 2010.geneva 2011.

xvii. World Health Organization. The global burden of diseases 2004 update. Http/ / www Who. Int/ health info/global burden disease -2004 report update / 